\title{
Design for manufacturability of macro and micro products: a case study of heat exchanger design
}

Omidvarnia, F.; Weng Feng, L.; Hansen, H. N.; Sarhadi, A.; Lenau, T. A.; Mortensen, N. H.

Published in:

International Journal on Interactive Design and Manufacturing

Link to article, DOI:

$10.1007 / \mathrm{s} 12008-018-0457-9$

Publication date:

2018

Document Version

Peer reviewed version

Link back to DTU Orbit

Citation (APA):

Omidvarnia, F., Weng Feng, L., Hansen, H. N., Sarhadi, A., Lenau, T. A., \& Mortensen, N. H. (2018). Design for manufacturability of macro and micro products: a case study of heat exchanger design. International Journal on Interactive Design and Manufacturing, 12(3), 995-1006. https://doi.org/10.1007/s12008-018-0457-9

\section{General rights}

Copyright and moral rights for the publications made accessible in the public portal are retained by the authors and/or other copyright owners and it is a condition of accessing publications that users recognise and abide by the legal requirements associated with these rights.

- Users may download and print one copy of any publication from the public portal for the purpose of private study or research.

- You may not further distribute the material or use it for any profit-making activity or commercial gain

- You may freely distribute the URL identifying the publication in the public portal 


\section{International Journal on Interactive Design and Manufacturing (IJIDeM) Design for manufacturability of macro and micro products- a case study of heat exchanger design \\ --Manuscript Draft--}

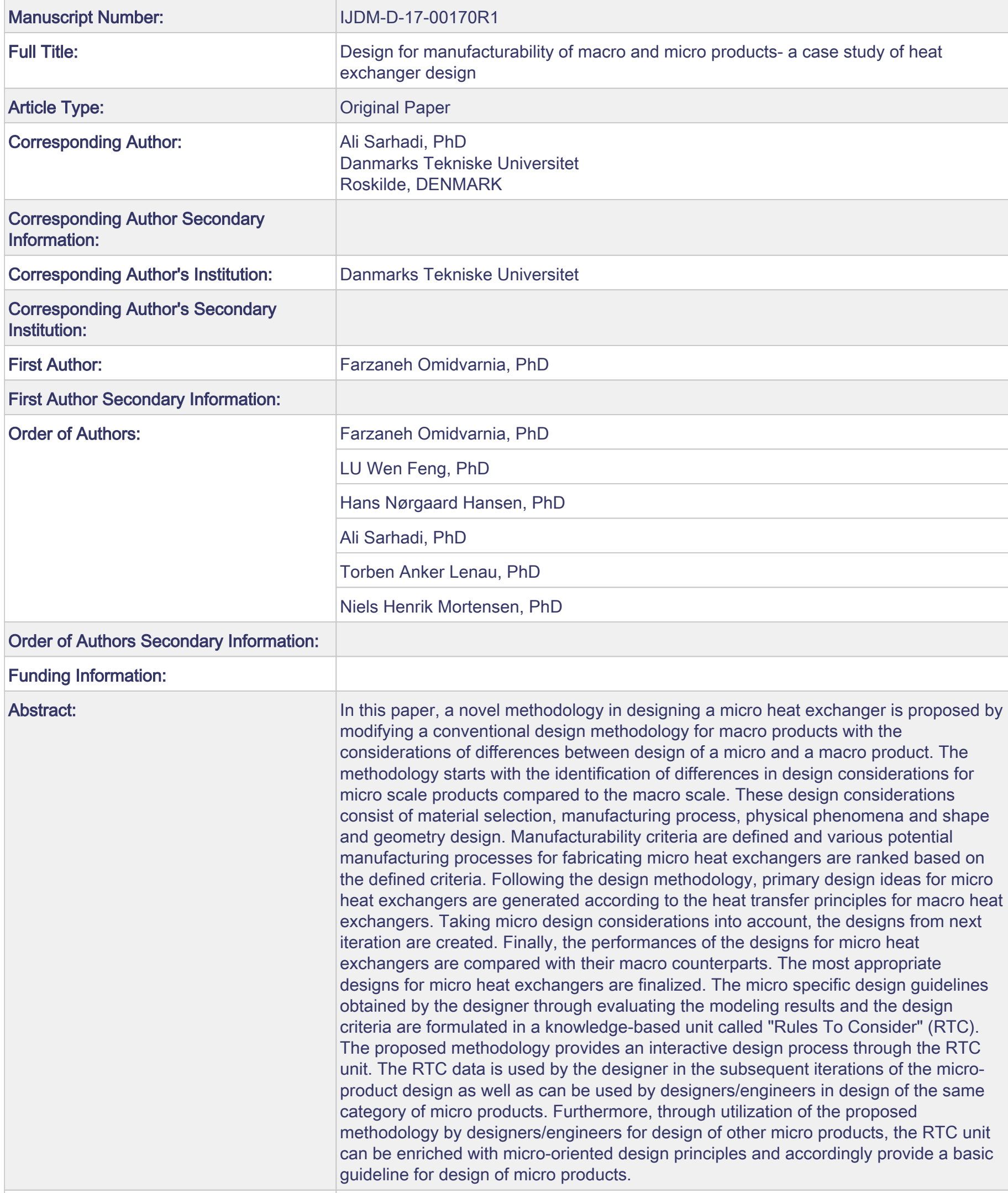

We would like to thank the Editor and the reviewers for their constructive comments. 


\section{Design for manufacturability of macro and micro products- a case study of heat exchanger design}

${ }^{1}$ Omidvarnia F., ${ }^{2}$ Weng Feng L., ${ }^{1}$ Hansen H. N., ${ }^{3 *}$ Sarhadi A., ${ }^{1}$ Lenau T. A., ${ }^{1}$ Mortensen N. H.

${ }^{1}$ Department of Mechanical Engineering, Technical University of Denmark (DTU), Kgs Lyngby 2800, Denmark

${ }^{2}$ Department of Mechanical Engineering, Faculty of Engineering, National University of Singapore (NUS), Singapore 117576, Singapore

${ }^{3}$ Department of Wind Energy, Technical University of Denmark (DTU), Roskilde 4000, Denmark

${ }^{*}$ Corresponding author. Tel.: +45 93513505

E-mail address: asar@dtu.dk 


\title{
Design for manufacturability of macro and micro products- a case study of heat exchanger design
}

\begin{abstract}
In this paper, a novel methodology in designing a micro heat exchanger is proposed by modifying a conventional design methodology for macro products with the considerations of differences between design of a micro and a macro product. The methodology starts with the identification of differences in design considerations for micro scale products compared to the macro scale. These design considerations consist of material selection, manufacturing process, physical phenomena and shape and geometry design. Manufacturability criteria are defined and various potential manufacturing processes for fabricating micro heat exchangers are ranked based on the defined criteria. Following the design methodology, primary design ideas for micro heat exchangers are generated according to the heat transfer principles for macro heat exchangers. Taking micro design considerations into account, the designs from next iteration are created. Finally, the performances of the designs for micro heat exchangers are compared with their macro counterparts. The most appropriate designs for micro heat exchangers are finalized. The micro specific design guidelines obtained by the designer through evaluating the modeling results and the design criteria are formulated in a knowledge-based unit called "Rules To Consider" (RTC). The proposed methodology provides an interactive design process through the RTC unit. The RTC data is used by the designer in the subsequent iterations of the micro-product design as well as can be used by designers/engineers in design of the same category of micro products. Furthermore, through utilization of the proposed methodology by designers/engineers for design of other micro products, the RTC unit can be enriched with micro-oriented design principles and accordingly provide a basic guideline for design of micro products.
\end{abstract}

Keywords: Design methodology, Design for manufacturing, Micro manufacturing, Size effect, Heat exchanger

\section{Introduction}

Minimizing the dimensions of the conventional systems and at the same time maximizing their performance is challenging, especially when auxiliary devices have to be eliminated from the system in order to reach the minimum size. It has been recognized that the size effects in micro scale (i.e. compared to macro size) brings complications in the design process of micro products. Also, considering the manufacturing constraints and the limited number of the available micro fabrication techniques, mass production of the designed micro products with acceptable cost is another challenging issue. To overcome the mentioned challenges for design of a micro product, modified design techniques or additional design steps are expected compared to design of the macro counterpart. An almost total lack of specific design strategies for micro products affects the development of these miniature components and limits the designers to the common traditional solutions [1]. A systematic methodology for the design process of micro products from the idea generation phase to manufacturing stage would be useful to obtain the most reliable and functioning design solution. 
So far, no published research has been particularly done to discuss if there is one or more deviation point in the design steps for micro products compared to the macro scale. This study aimed to find the answers of the following question:

- Where is the deviation point in the steps of design for micro manufacturing compared to the macro scale?

To investigate the possible differences in the design process, the design procedure of a micro heat exchanger in comparison with its 10 times scaled up corresponding is studied in this paper.

Micro channel compact heat exchangers have become extensively widespread due to their benefits of reduced dimensions and increased thermal performance [2,3]. Need for micro scale heat exchangers mainly arose because of the requirement of miniature size and light weight in a number of industrial applications. The development of micro heat exchangers have been the subject of several research works [4-8]. A wide variety of Micro Electro Mechanical Systems (MEMS) heat exchangers as well as non-MEMS micro heat exchangers have been developed in order to dissipate the heat from the devices such as computer CPUs. Thermal performance of micro heat exchangers of different materials including micro heat exchanger fabricated from aluminum alloy substrate [9], ceramic micro heat exchanger manufactured by the Pressure Laminated Integrated Structures (PLIS) process [10] and stainless steel counter-flow micro heat exchangers [11] has been investigated.

In spite of several research works on design of micro products such as micro heat exchangers, design for micro manufacturing still lacks a micro oriented design methodology by taking the design considerations in micro scale into account. Thus, the current paper intends to modify a conventional design methodology by taking the design considerations in micro scale into account and subsequently implement the modified design methodology to characterize the differences between the design of a micro and a macro heat exchanger.

In this paper, the general design steps for designing a conventional product are described followed by the analysis of differences in the design process of micro and macro products. In section 3, design considerations in micro scale are presented and the proposed micro specific methodology used for designing the micro heat exchanger in this study is introduced. A manufacturability criterion is defined and potential manufacturing processes for fabrication of a micro heat exchanger are ranked based on the defined criterion. Then, different phases of the proposed design methodology are discussed in parallel with designing the micro heat exchanger. Finally, the results of the simulations and comparison of both micro heat exchanger and its 10 times scaled up macro counterpart are presented, besides the conclusion of the study.

\section{Common steps in design methodology}

Generally, the main steps in the design process of conventional macro products $[12,13][14]$ can be well imitated in design for micro components. Getting inspired by the methods described by Cross [14], design of both macro and micro components the process starts with problem definition, where the reason for creating a new product is described and the need for such product is formulated. The initial expectations from the target product are usually investigated by establishing functions and the essential constraints and key requirements are defined in a so-called setting the requirement phase. The expected benefits of the product are expressed in terms of design requirements or design specifications. Many other important objectives have to be obtained apart from the main function of a product, such as low cost, easy manufacturability, overall performance, high product reliability, low environmental impact etc. [15]. Consequently, initial alternatives are generated based on the defined need (idea generation). In the detailed design phase, choice of materials, definition of part geometry and tolerances are determined together with production processes, tooling and quality assurance methods [15]. Next, the selected ideas are analyzed and evaluated (analysis phase) based on the required functions and criteria. The generated ideas gradually improve after several design iterations until the most desirable design idea is created. 


\section{Framework of the micro heat exchanger design}

In spite of the above discussed similarities, there are differences between the design process of the micro and the macro components. According to the experiences gained through the design of a micro heat exchanger in a previous study [16], the differences mainly appear from the second design iteration onwards (see

Fig. 1). The systematic design approach described by cross [14] is applied as the inspiring model for design of the micro heat exchanger. During the first design iteration general ideas are created based on the macro conventional design requirements regarding the target product (e.g. in design of a macro heat exchanger, large thermal contact surface and high thermal conductivity of the heat exchanger's constituent material are some of the design requirements). The generated ideas are then passed through the primary numerical analysis and evaluation (see

Fig. 1). The selected initial ideas after this primary analysis are ready to get modified by the micro specific design consideration. Even though the design requirements (i.e. large thermal contact surface and high thermal conductivity) are considered as the starting point in design of the micro heat exchanger, they could be updated during the subsequent design evaluations by taking into account the micro specific design considerations. These considerations are mainly arising from the dissimilarities between micro and macro scale in the following categories:

- $\quad$ Shape and feature design

- $\quad$ Physical phenomena due to the size effect

- Material selection

- Manufacturing processes

Then, by taking the considerations for material selection, manufacturing process, physical phenomena and shape and geometry design into account, the second design ideas are created. Functional performance (i.e. thermal performance) of the generated ideas is analyzed by numerical simulation and the ideas are assessed based on the design criteria (i.e. functional performance and manufacturability). If the design criteria are satisfied, the design ideas are selected and optimized as the final design. Otherwise, the design iteration continues. The micro specific feedbacks gained during the analysis of the selected ideas in each evaluation cycle are formulated as guidelines in a step called "Rules To Consider" (RTC) unit and will be implemented for the next iteration of the design. Since the existing knowledge regarding size effect on micro scale is not as comprehensive as the available knowledge on the conventional macro scale, the outcome of the simulations and analysis of a specific micro product might be a new data to be added to the existing database. Therefore, the RTC unit has been defined to be filled with the probable new findings during the design process of a micro product which can be used in the next design iteration of that micro product as well as in the design process of another micro product in the same category. In other word, the designer analyzes the modeling results during the design evaluation in each iteration, and accordingly the micro design principles arising from the size effect in micro scale are identified and stored in the Knowledge-based RTC unit. The RTC unit is the place where the designer interacts with the methodology and affects the design requirements and consequently the idea generation phase. In fact the design methodology is an interactive design process where the designer analyzes the modeling results in each iteration, and based on the analysis as well as the design criteria (i.e. functional performance and manufacturability) formulates micro specific design rules for that specific category of micro products (i.e. micro heat exchanger in our case) in the RTC unit. Theses RTC data can be used by designer/engineers in the design of the same category of micro products. In addition, the RTC unit can be developed and generalized through using the proposed methodology by designers/engineers in the design of other micro products.

Fig. 1 depicts the schematic presentation of the design methodology for micro product. The first part of the design methodology, indicated by the upper segment, is common between the micro and macro design, but the second part (lower segment) is the micro specific part of the design methodology (see 
Fig. 1). In the next sections, the presented design methodology is implemented to design of a micro heat exchanger and the thermal performance of the final micro designs are compared with its 10 times scaled up macro counterparts.

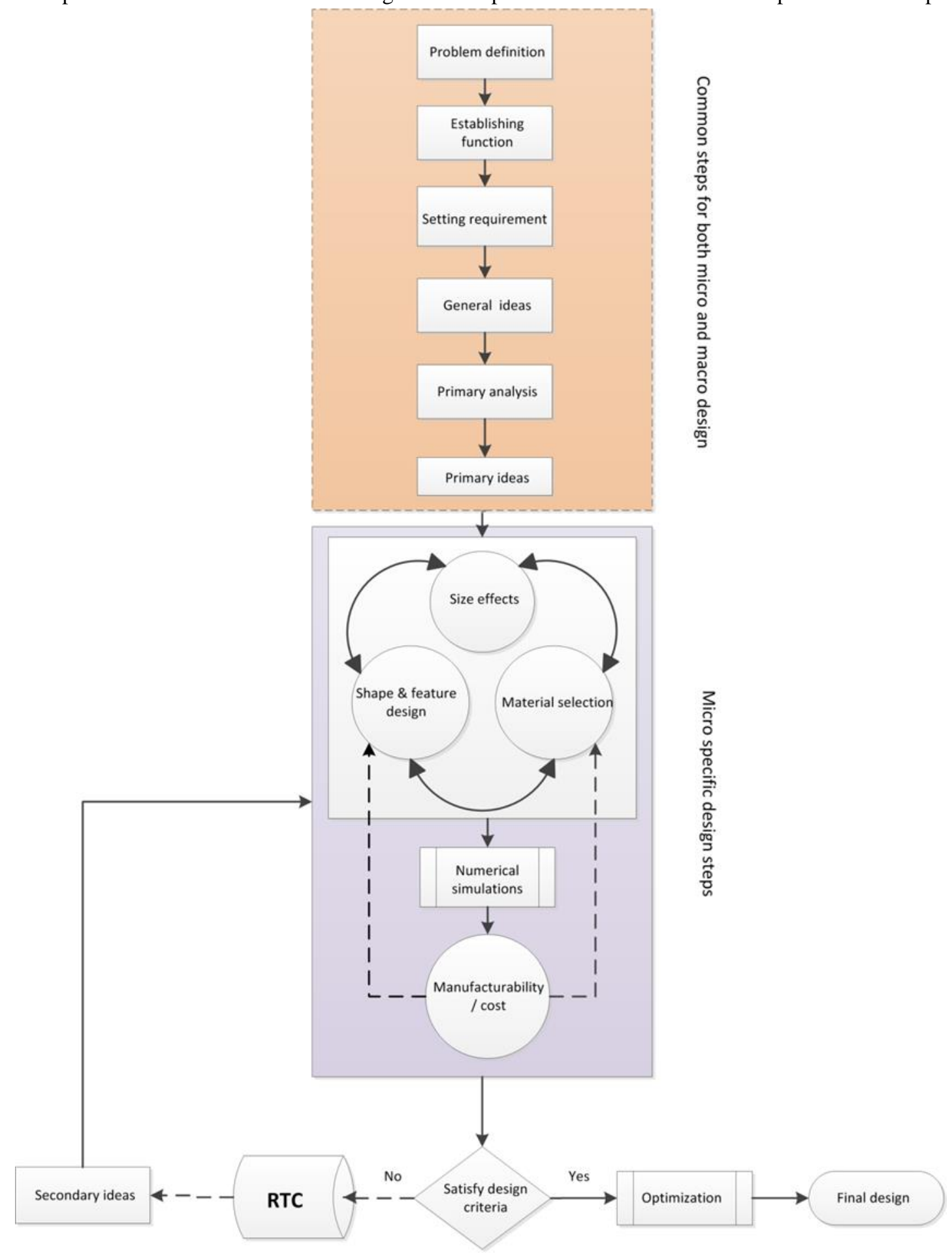

Fig. 1. Schematic of the micro specific suggested design methodology; the correspondences (upper part) and differences (lower part) in design steps for macro and micro manufacturing 


\subsection{Primary design}

Primary design ideas for micro heat exchangers are suggested based on the heat transfer principles for design of its macro counterparts (see Fig. 2). Thermal contact surface, heat transfer coefficient at the contact interfaces, and thermal conductivity of the heat exchanger constituent material are the influential parameters on the thermal performance of a heat exchanger. The micro heat exchanger is expected to keep the temperature of a heat source (e.g. a CPU) bellow $50^{\circ} \mathrm{C}$. In the following sections, considerations for micro products (i.e. material selection, manufacturing process, etc.) are discussed and the improved design ideas for the micro heat exchanger are suggested based on these micro specific considerations.
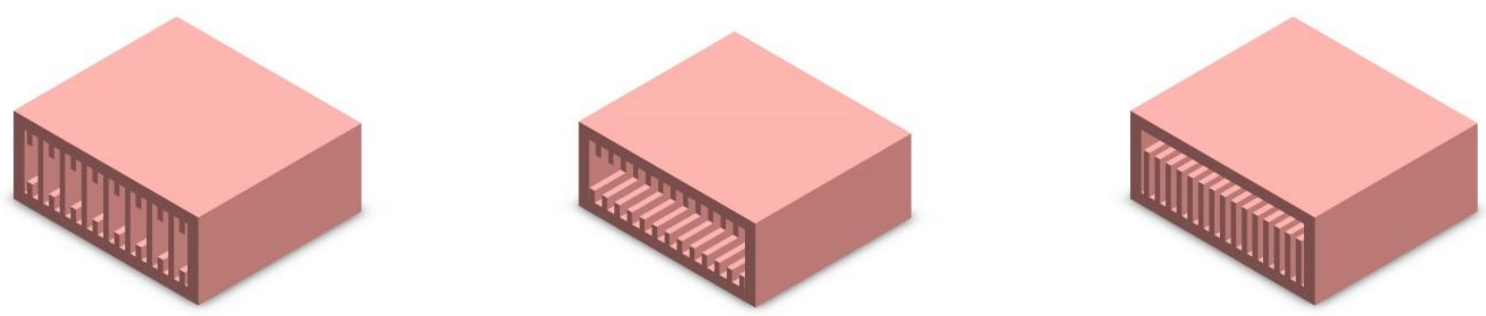

Fig. 2. The initial proposed micro fluidic heat exchangers

\subsection{Design considerations in micro scale products}

\section{a. Material selection}

Material selection in micro manufacturing is significantly limited by availability of the suitable fabrication techniques and materials for mass production. In addition, the size effects on the properties of the selected material (e.g. mechanical, thermal, chemical, electrical etc.) needs to be considered as the material behavior can be completely different compared to macro scale. Therefore, decision making based on the inevitable mutual interaction between the manufacturing process and the selected material is very important in the design phase [17].

Copper is selected as the potential material for fabrication of the micro heat exchanger due to its high thermal conductivity. Considering the restrictions in selecting the compatible materials with the available micro manufacturing techniques, aluminum is also selected as another alternative (Table 1).

Table 1 Thermal conductivity (W/m-K) of various materials at $300 \mathrm{~K}$ [18]

\begin{tabular}{|l|l|}
\hline Material & Thermal conductivity \\
\hline Copper & 401 \\
\hline Aluminum & 237 \\
\hline PMMA & 0.19 \\
\hline
\end{tabular}

Since polymer components are usually subjected to less manufacturing constraints, the potential micro heat exchangers made from the combination of polymer (e.g. PMMA) and metal is also investigated in this study and the probable differences in their thermal performance compared to the fully metal micro heat exchangers are studied. The high mechanical stability of the polymer components besides the slight limitations in design rules provides the optimum realization of a concept into a product. As an example, the fabrication of free form surfaces in polymer is very easy [19]. Some manufacturing processes such as micro injection molding is highly applicable and cost effective for high volume fabrication of micro components. In this case, metal (i.e. copper/aluminum) is considered as the contact surface material between the heat exchanger and the heat source, and polymer as the rest of the body (see Fig. $4 \mathrm{C}_{2}$ ). Sealing of the metal and polymer components is required for the formation of enclosed fluid chamber. It is assumed that the polymer part is attached to the metal part through an adhesive bonding technique such as gluing. Because of the simplicity of adhesive bonding, this approach has been extensively used for 
sealing thermoplastic microfluidic chips [20]. Thermal performance of both micro and macro heat exchangers made of copper or aluminum, and also the combination of metal and polymer are evaluated and compared to each other in this study.

\section{b. Manufacturing process}

The feasibility of realizing a design idea in micro scale is dependent on different factors including the manufacturability. Since the micro manufacturing techniques are often categorized as MEMS manufacturing and non-MEMS manufacturing [17], the material selection and manufacturing techniques used for fabrication of these categories are significantly different. In general, some of the technologies relating to design and fabrication of micro heat exchangers (regardless of being MEMS or non-MEMS) with hydraulic diameter of less than 200 micrometers can be listed as: LIGA, Chemical Etching, Stereolithography, and micro-machining [21]. However, considering the non-MEMS based heat exchangers in this study, and the required material with acceptable thermal properties, some of the micro manufacturing techniques and their suitability for mass production of the non-MEMS based micro heat exchangers are discussed. Generally, micro manufacturing is the production of products whose functional features or at least one

dimension are in the order of micro meter [15]. Therefore, the manufacturing techniques associated with the selected heat exchangers can be classified as micro manufacturing.

Due to the fact that disassembly and assembly of the micro products are challenging issues, the idea of repairing the worn out component is not applicable in micro manufacturing; as an alternative, replacing the damaged component with a new one is more cost effective and practical in this scale. Thus, the need for replacing the inlet/outlet in micro heat exchanger is not essential as in the case of a damaged inlet/outlet, the entire heat exchanger would be replaced with a new one. Consequently, the same life span cannot be considered for micro and macro heat exchangers.

\section{- Review of micro manufacturing techniques for fabrication of micro heat exchangers}

The comparison between design for manufacturing of micro and macro components can be made by dividing the entire process into two sub-processes as "design" and "manufacturing". Conventionally, the design process and manufacturing can be separated as two independent procedures, even though the manufacturing possibilities are considered during the concept generation. However, in design for micro manufacturing, there is a strong interconnection between design and manufacturing and they cannot be considered as two separate processes (Fig. 3). This is mainly due to the size effects in micro scale and its consequence on the manufacturing constraints that restricts the applicability of most of the conventional manufacturing technologies such as cutting, forming etc.

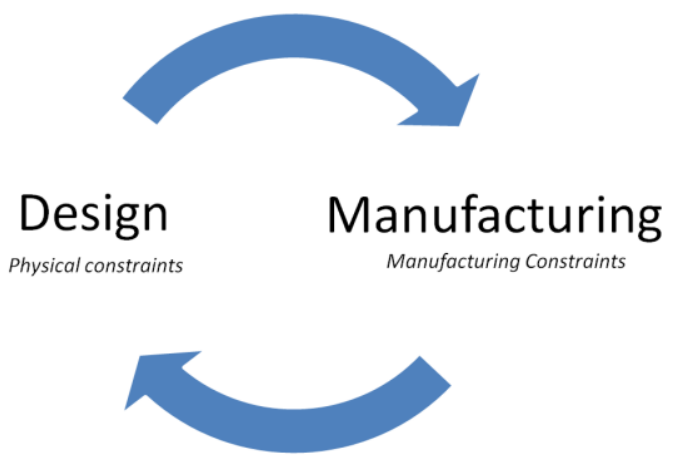

Fig. 3. The interdependence between design and manufacturing process in design for micro manufacturing

Functional performance and manufacturability are identified as two main criteria in design of the micro heat exchanger in this study. The manufacturability of the micro heat exchanger depends on several fabrication principles such as feature size, feature shape, material, surface finish on the interface between heat exchanger and heat source, precision, mass production, and cost. Table 2 presents several potential manufacturing processes as the most suitable methods for fabricating the micro heat exchanger with/without fins. The manufacturing processes are compared and ranked based on their potential to meet the 
defined fabrication criteria. Each fabrication criteria is weighted based on its importance from 1 to 5 where 1 and 5 represent the lowest and the highest level, respectively. The scores are summed and the highest score represent the most suitable manufacturing process for fabricating the micro heat exchanger (see Table 2). Using the weighted objective method, the highest score represents the most suitable manufacturing process for fabricating the micro heat exchanger (see Table 2).

Table 2 Manufacturing processes versus fabrication criteria for part quantity over 1000 ( 1 and 5 represent the least and the most suitable manufacturing processes, respectively); the scores of the hashed cells are not counted in the total score.

\begin{tabular}{|c|c|c|c|c|c|c|c|c|}
\hline \multirow[b]{3}{*}{$\begin{array}{c}\text { Manufacturing } \\
\text { process }\end{array}$} & \multicolumn{7}{|c|}{ Fabrication criteria } & \multirow{3}{*}{$\begin{array}{l}\text { Total } \\
\text { score }\end{array}$} \\
\hline & \multirow{2}{*}{$\begin{array}{c}\text { Feature size } \\
\text { (wall/fin } \\
\text { thickness } \\
<500 \mu \mathrm{m} \text { ) }\end{array}$} & \multirow[b]{2}{*}{$\begin{array}{c}\text { Feature } \\
\text { shape }\end{array}$} & \multicolumn{2}{|c|}{ Material } & \multirow{2}{*}{$\begin{array}{l}\text { surface } \\
\text { finish }\end{array}$} & \multirow{2}{*}{ precision } & \multirow[b]{2}{*}{$\begin{array}{c}\text { mass } \\
\text { production / } \\
\text { cost }\end{array}$} & \\
\hline & & & Copper & Aluminum & & & & \\
\hline Weight & 1 & 1 & & 1 & 1 & 1 & 4 & \\
\hline Micro end milling & 5 & 5 & 4 & 5 & 4 & 4 & 2 & 31 \\
\hline Micro EDM & 5 & 5 & 5 & 5 & 5 & 5 & 1 & 29 \\
\hline $\begin{array}{l}\text { Micro metal } \\
\text { injection molding } \\
(\mu \mathrm{MIM})\end{array}$ & 4 & 4 & 3 & 4 & 2 & 2 & 4 & 32 \\
\hline Micro casting & 3 & 3 & 2 & 4 & 1 & 1 & 3 & 24 \\
\hline Micro extrusion & 4 & 2 & 1. & 5 & 3 & 3 & 5 & 37 \\
\hline
\end{tabular}

Depending on the required part quantity, decision on manufacturing technique selection can be made. For instance, due to the high cost of mold design and production, for producing the part quantity less than 1000 the manufacturing techniques such as micro end milling and micro EDM are considered as the most suitable alternatives. However, in order to mass volume fabrication of the parts (i.e. over 1000 parts) applying the manufacturing techniques such as $\mu$ MIM or micro extrusion is more appropriate. Regarding the material selection, copper has higher thermal conductivity (see Table 1) compared to aluminum; however, as seen from Table 2, aluminum has a better score in manufacturability. As later will be shown, using copper instead of aluminum does not improve the thermal performance of the micro heat exchanger considerably. Therefore aluminum is selected as the fabrication material. Considering aluminum as the fabrication material, the need for mass production and high capability of the micro extrusion process (see Table 2) in production of metal components such as aluminum, this process is selected among the other manufacturing techniques.

\section{c. Size effect and physics}

Downscaling a fluidic device alters the fluid flow behavior inside the device due to dominance of surface forces on the body forces in the micro scale [22]. In other words, inertial forces become quite small compared to the surface forces such as viscous forces. This means that the Reynolds number in micro scale decreases proportional to the length scale, hence laminar flow regime is expected. In case of fluidic heat exchangers, the convective heat transfer coefficient $(h)$ at the solid-fluid interface declines with decreasing the Reynolds number, therefore affects the thermal performance of the heat exchanger. Furthermore, thermal resistance is inversely proportional to the cross sectional area (perpendicular to the heat transfer 
direction). Thus, some micro features such as micro fins in the heat exchanger have considerably high thermal resistance and in some cases its thermal efficiency reduces significantly.

In order to evaluate the thermal performance of the heat exchangers, the heat transfer and fluid flow equations are solved simultaneously in a finite element (FE) model in COMSOL software. The steady state form of the governing momentum, mass and energy conservation equations are expressed as [23, 24]:

$$
\begin{aligned}
& \rho u \cdot \nabla u=-\nabla P+\nabla \cdot\left(\mu\left(\nabla u+(\nabla u)^{T}\right)-\frac{2}{3} \mu(\nabla \cdot u) \mathrm{I}\right)+F \\
& \nabla \cdot(\rho \mathrm{u})=0 \\
& \rho C_{p} u . \nabla T=\nabla \cdot(\mathrm{k} \nabla T)+Q
\end{aligned}
$$

where $\rho, \mathrm{u}, P, \mu, F, C_{p}, \mathrm{k}, Q$ are density, velocity vector, pressure, dynamic viscosity, body force vector, specific heat capacity, thermal conductivity and heat source, respectively.

\section{d. Shape and feature design}

Manufacturing of macro products with normal to complex geometries is usually not problematic, but this is a big challenge when it comes to micro scale. For instance, although making holes, slots, threads, etc. is easily feasible in macro manufacturing, this may be very difficult to achieve in micro fabrication. Therefore, in design of a micro product, its geometric shape should not be directly downscaled, but it should be modified to meet the micro manufacturing constraints. Any micro feature or geometric shape that is complex in micro manufacturing should be avoided, unless it has a key role in the performance of the micro product. In other words, the effect of a micro feature or geometric shape on performance of a micro product should be assessed carefully regardless of its role in its macro counterpart. For instance, in a macro heat exchanger, fins improve the thermal performance in two ways: increasing the thermal contact surface, and increasing the probability of turbulent flow and accordingly enhancing the convective heat transfer coefficient. In a micro heat exchanger, adding micro fins can enlarge the thermal contact surface, but the turbulent flow is not the case in a micro heat exchanger, unless under an extremely high pressure gradient that the flow can achieve a sufficiently high velocity. The effects of micro fins are assessed by comparing the thermal performance of micro heat exchangers with fins against their counterparts in the same dimensions, but without fins in the next sections.

\subsection{Second design}

Taking considerations for material selection, manufacturing process, physical phenomena and shape design, the initial designs are updated (see Fig. 4). The new designs shown in Fig. 4 only represent the body of the heat exchanger as the fluid chamber, and lids, inlets and outlets are not included in the designs. In the new designs, it is suggested to investigate the possibilities for combining high thermal conductively materials with the low conductive ones that satisfy the constraints on the manufacturing and the geometric shape in the micro domain. In the next section, the suggested second designs are evaluated and compared with their macro counterparts.

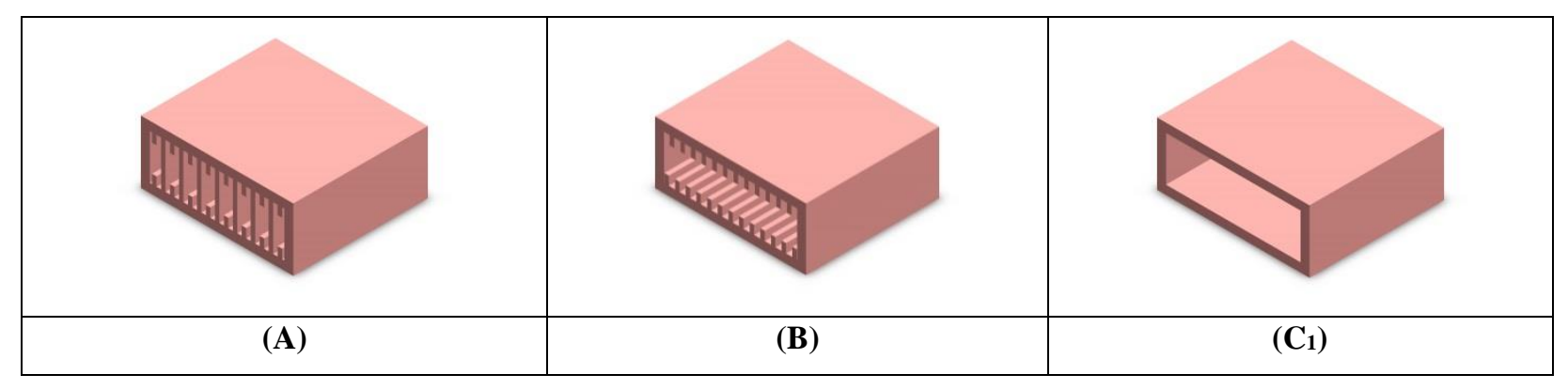




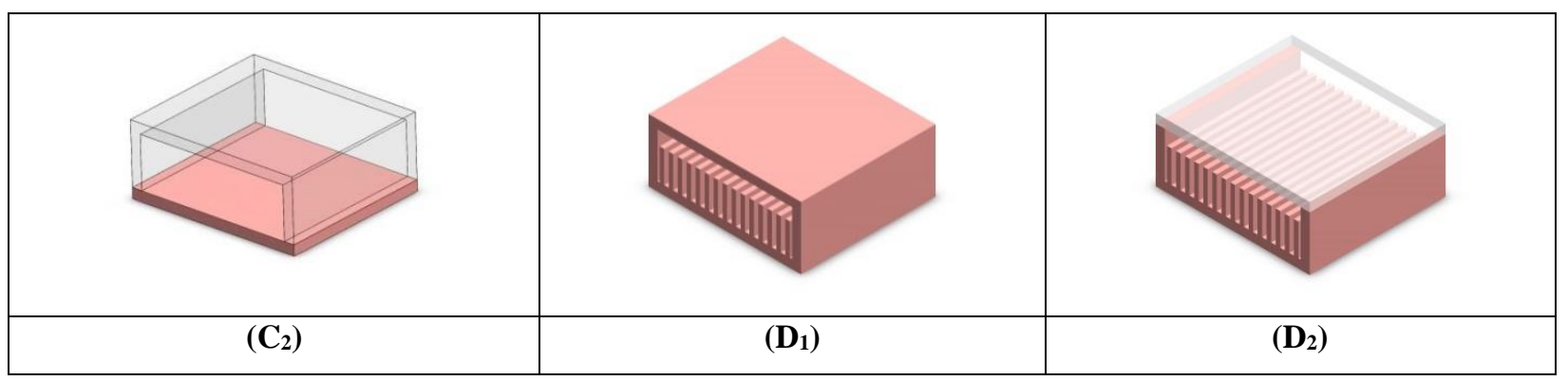

Fig. 4. Second designs for the micro heat exchanger

\section{Final evaluation and decision making}

In order to compare and evaluate the thermal performances of the suggested micro heat exchangers and their 10 times scald up macro counterparts in Fig. 4, the thermal analysis of the selected designs was carried out using FE simulation of the conjugate heat transfer (Eqs. 1-3) in COMSOL. Different constituent materials (copper, aluminum and combination of polymer and metal) were also considered in the FE simulation. Water was considered as coolant flowing under a laminar flow regime in the heat exchanger. A convective heat transfer to the ambient air was considered for the surfaces of the heat exchanger and heat source. Thermal boundary conditions for both micro and macro heat exchangers are given in Table 3 . Geometrical design parameters (i.e. width, height and the distance between fins) of the micro heat exchangers (see Fig. 5a) were optimized for minimum heat source temperature in a previous study [16]. The optimized geometrical dimensions of the micro heat exchangers are given in

Table 4. The heat source is considered as a rectangular cube with the same external dimensions of the micro heat exchanger $(17 \times 15 \times 7 \mathrm{~mm})$. For purpose of comparing micro and macro heat exchangers, the dimensions of the heat source are also scaled up by 10 times for macro heat exchangers. Fig. 5 depicts the schematic view of the heat exchanger geometrical parameters as well as the schematic of the micro heat exchanger mounted on the heat source. The steady state results for heat source temperatures are given in Table 5. "The heat source temperature in the steady state condition represents the thermal performance of the heat exchanger".

Table 3 Thermal boundary conditions for both micro and macro heat exchangers

\begin{tabular}{|l|l|}
\hline $\begin{array}{l}\text { Inlet velocity of the coolant } \\
(\mathrm{m} / \mathrm{s})\end{array}$ & 0.066 \\
\hline $\begin{array}{l}\text { Heat source/heat exchanger } \\
\text { Interface HTC }\left(\mathrm{W} / \mathrm{m}^{2} . \mathrm{K}\right)\end{array}$ & 2000 \\
\hline $\begin{array}{l}\text { Heat source power per volume } \\
\left(\mathrm{W} / \mathrm{m}^{3}\right)\end{array}$ & $5.6 \times 10^{6}$ \\
\hline $\begin{array}{l}\text { Inlet temperature of the coolant } \\
(\text { water })(\mathrm{C})\end{array}$ & 20 \\
\hline $\begin{array}{l}\text { Convective heat transfer } \\
\text { coefficient of the ambient } \\
\left(\mathrm{W} / \mathrm{m}^{2} . \mathrm{K}\right)\end{array}$ & 10 \\
\hline
\end{tabular}

Table 4 Geometrical dimensions of the micro heat exchangers

\begin{tabular}{|c|c|c|c|c|c|}
\hline $\begin{array}{c}\text { Heat Exchanger } \\
\text { type }\end{array}$ & $\begin{array}{c}\text { Dimension } \\
(\mathbf{m m} \times \mathbf{m m} \times \mathbf{m m})\end{array}$ & $\begin{array}{c}\text { Wall thickness } \\
(\mathbf{m m})\end{array}$ & $\begin{array}{c}\text { Fin width } \\
(\mathbf{m m})\end{array}$ & $\begin{array}{c}\text { Fin Height } \\
(\mathbf{m m})\end{array}$ & $\begin{array}{c}\text { Distance between fins } \\
(\mathbf{m m})\end{array}$ \\
\hline
\end{tabular}




\begin{tabular}{|c|c|c|c|c|c|}
\hline$(\mathrm{A})$ & $17 \times 15 \times 7$ & 1 & 0.8 & 0.6 \\
\hline$(\mathrm{B})$ & $17 \times 15 \times 7$ & 1 & 0.8 & 1.75 \\
\hline$\left(\mathrm{C}_{1}\right)$ & $17 \times 15 \times 7$ & 1 & - & \\
\hline$\left(\mathrm{C}_{2}\right.$ & $17 \times 15 \times 7$ & 1 & - & - \\
\hline$\left(\mathrm{D}_{1}\right)$ & $17 \times 15 \times 7$ & 1 & 0.8 & - \\
\hline$\left(\mathrm{D}_{2}\right)$ & $17 \times 15 \times 7$ & 1 & 0.8 & 3.5 \\
\hline
\end{tabular}

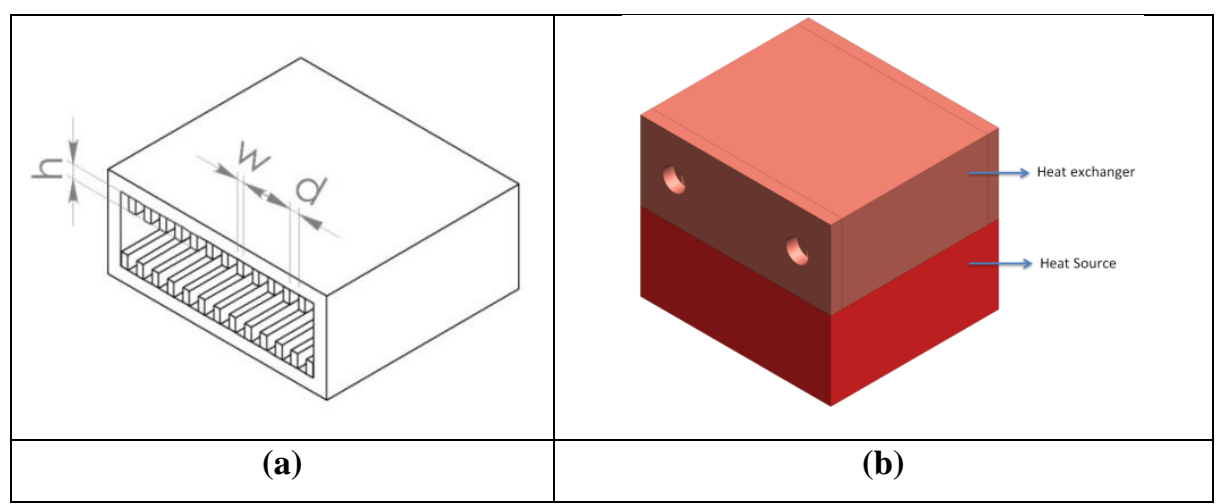

Fig. 5. (a) The schematic of the heat exchanger and its geometrical parameters (b) the schematic of the micro heat exchanger mounted on the heat source

Table 5 The result of thermal analysis for both micro and macro heat exchangers with different geometric shapes and materials

\begin{tabular}{|c|c|c|c|c|c|c|c|c|c|c|c|c|c|}
\hline \multicolumn{2}{|c|}{$\begin{array}{l}\text { Heat Exchanger } \\
\text { type }\end{array}$} & \multicolumn{2}{|c|}{$\mathbf{A}$} & \multicolumn{2}{|c|}{ B } & \multicolumn{2}{|c|}{$\mathrm{C}_{2}$} & \multicolumn{2}{|c|}{$\mathrm{C}_{1}$} & \multicolumn{2}{|c|}{$\mathbf{D}_{2}$} & \multicolumn{2}{|c|}{$\mathbf{D}_{1}$} \\
\hline \multicolumn{2}{|c|}{ Material } & 音 & $\overline{\tilde{o}}$ & 音 & 产 & 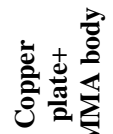 & 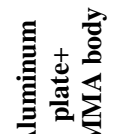 & 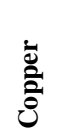 & 音 & 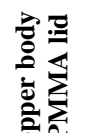 & 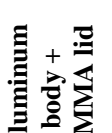 & 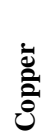 & 音 \\
\hline \multirow{2}{*}{$\begin{array}{l}\text { Heat } \\
\text { source } \\
\text { tempe } \\
\text { rature } \\
\left({ }^{\circ} \mathbf{C}\right)\end{array}$} & Micro & $F$ & 过 & $\stackrel{9}{7}$ & $\stackrel{+}{\dot{g}}$ & $\vec{j}$ & $\widehat{\leftarrow}$ & $\hat{\dot{g}}$ & $\bar{F}$ & $\stackrel{\infty}{\stackrel{+}{+}}$ & $\stackrel{?}{\exists}$ & $\stackrel{\infty}{\stackrel{f}{\vec{f}}}$ & $\vec{F}$ \\
\hline & Macro & 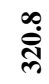 & 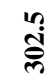 & $\stackrel{\infty}{\stackrel{\oplus}{\circ}}$ & חొ & 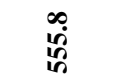 & $\stackrel{\partial}{\vec{t}}$ & $\begin{array}{l}\infty \\
\stackrel{+}{*} \\
\stackrel{+}{\sigma}\end{array}$ & ָ̊ & 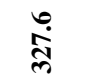 & $\stackrel{\circ}{\circ}$ & 今े & $\stackrel{+}{\dot{f}}$ \\
\hline
\end{tabular}

Initially, it is expected that fins have a significant role in the improvement of thermal performance for both micro and macro heat exchangers by increasing the thermal contact surface. However, as can be seen from the thermal analysis results in Table 5 and Fig. 6, the effect of fins on improving thermal performance in macro heat exchangers is significantly higher than that for its micro counterparts. Comparing the heat exchangers with and without fins with the same geometry and material (see Fig. 6) reveals that presence of fins in micro heat exchangers reduces the heat source temperature only around 3-7\%, while the temperature reduction for their macro counterparts is around $29-58 \%$. This can be explained by evaluating the convection heat transfer at the solid-fluid interface as expressed by Newton's law of cooling [25]: 


$$
q=-h A\left(T_{s}-T_{\infty}\right)
$$

Where $h, A, T_{s}$ and $T_{\infty}$ are convective heat transfer coefficient, solid-fluid contact surface, solid surface temperature and fluid temperature, respectively. For instance, presence of the fins in heat exchanger type A increases the contact surface to a ratio of 3.1:1(see Table 6) for both micro and macro heat exchangers. Therefore, difference in thermal performance of the fins for macro compared to the micro heat exchanger should be related to the other parameters, namely convective heat transfer coefficient $(h)$ and temperature gradient $\left(T_{s}-T_{\infty}\right)$. $h$ increases with increasing the Reynolds number which is proportional to length scale and is considerably higher in case of macro heat exchanger than that for the micro one $\left(\frac{\operatorname{Re}_{\text {macro }}}{\operatorname{Re}_{\text {micro }}} \approx 10\right)$. Hence, $h$ is larger for the macro heat exchanger (refer to Section 3.2c). Moreover, due to small cross sectional area of the fins in the micro heat exchanger, the thermal resistance of the fins in the micro heat exchanger is considerably higher than that for the macro one which results in considerable temperature gradient between the base and the tip of the fins. This decreases the temperature difference between the solid surface and the fluid $\left(T_{s}-T_{\infty}\right)$; therefore, reduces the fin's thermal performance.

Based on the results, presence of the fins has an insignificant role on thermal performance of the micro heat exchanger while, as mentioned before (refer to section $3.2 \mathrm{~d}$ ), it can considerably raise the manufacturing costs and challenges.

Table 6 Solid-fluid contact surface for both micro and macro heat exchangers type A (a) without fins (b) with fins

\begin{tabular}{|c|c|c|}
\hline \multirow{2}{*}{ Heat Exchanger type A } & \multicolumn{2}{|c|}{ Solid-fluid contact surface $\left(\mathrm{mm}^{2}\right)$} \\
\cline { 2 - 3 } & Micro & Macro \\
\hline (a) Without fins & 600 & 60000 \\
\hline (b) With fins & 1860 & 186000 \\
\hline
\end{tabular}

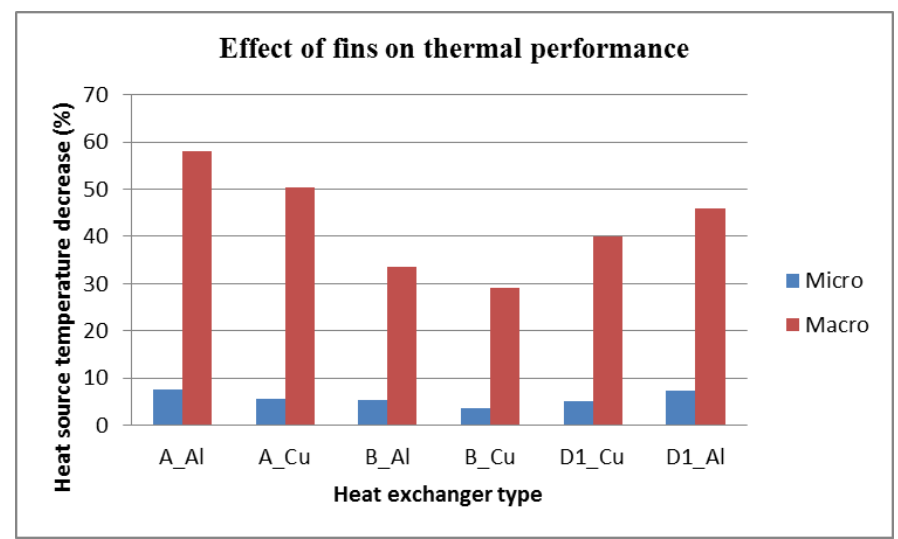

Fig. 6. Effect of fins on the thermal performance of the micro and macro heat exchangers (Al: Aluminum, $\mathrm{Cu}$ : Copper)

The effect of the heat exchanger constituent material on its performance in both micro and macro scales are presented in Table 5 and Fig. 7. Thermal performance of the heat exchangers entirely made of copper compared to ones made of aluminum show only a slight improvement around $1-4 \%$ in micro scale and around 6-11\% in macro scale (see Fig. 7a). For example, the difference between the heat source temperature for a micro copper heat exchanger and the micro aluminum one (A and $\mathrm{B}$ in Table 5) is less than $1^{\circ} \mathrm{C}$, while this difference is around $20^{\circ} \mathrm{C}$ for their macro counterparts. Furthermore, combining the metal (copper, aluminum) with the PMMA polymer increases the heat source temperature only around 0-5\% in micro scale and 1$22 \%$ in macro scale (see Fig. 7b). Considering $\mathrm{C}_{1}$ and $\mathrm{C}_{2}$ in Fig. 4, the difference in thermal performance between micro heat 
exchanger entirely made from copper $\left(42.9^{\circ} \mathrm{C}\right)$ and a copper plate as the interface material and a polymer body $\left(44.9^{\circ} \mathrm{C}\right)$ is only $2^{\circ} \mathrm{C}$ whereas this difference is around $100^{\circ} \mathrm{C}$ for their macro counterparts (see Table 5). The thermal performances of the micro and macro aluminum heat exchangers are also behaved in the same manner. In fact, high thermal resistance due to the small cross sectional area of the wall in the micro heat exchanger with hybrid materials does not play an important role in transferring heat except the copper plate. Due to lower thermal resistance because of larger cross sectional area in its macro counterpart the role of the body in transferring heat is considerable. Therefore, the selection of material has more noticeable effect on the thermal performance for macro scale.

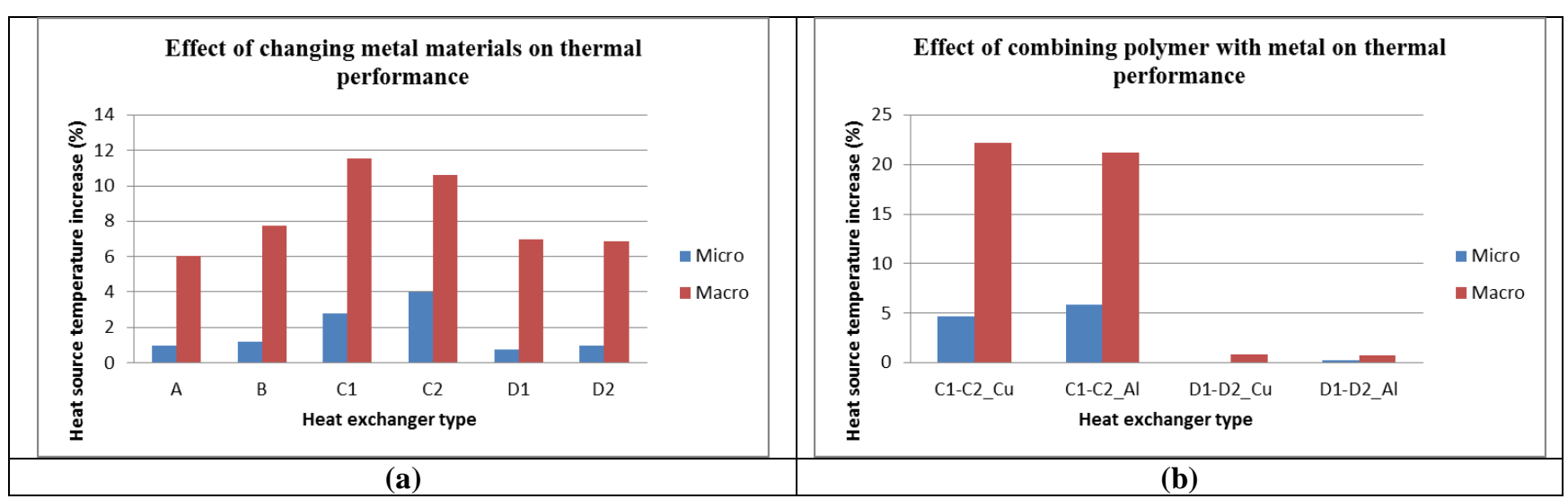

Fig. 7. Effect of the heat exchanger constituent materials on thermal performance of micro and macro heat exchangers (Al: Aluminum, $\mathrm{Cu}$ : Copper) (a) Changing the metal from copper to aluminum (b) Combining the metal (copper, aluminum) with PMMA polymer.

It can be concluded that the aluminum micro heat exchanger without fin can fulfil our design considerations as final design(Fig. 4- $\mathrm{C}_{1}$ ) due to the insignificant effect of the micro fins on the thermal performance of the micro heat exchangers (physical phenomena), the costs and challenges in fabricating the micro fins through the available manufacturing techniques (manufacturing process, shape and feature design), and the slight difference between the thermal performance of the micro heat exchanger made of copper and aluminum (material selection). In this case, the most applicable manufacturing technique would be extrusion with aluminum as explained before (refer to Section 3.2b). The lessons learned through analysis of the modeling results by the designer, i.e. the effects of different design parameters (i.e. constitutive materials, dimensions and arrangement of the fins, etc.) on the performance of a micro heat exchanger, form the RTC unit which can be used by designers/engineers in design of similar micro heat exchangers. In addition, designers/engineers can enrich the RTC unit with micro specific design principles by using the proposed methodology in design of other micro products. The more the methodology is used by designers/engineers in design of micro products, the more RTC unit get enriched with micro oriented design principles so that the proposed design methodology can serve as a primary guideline in design of micro products.

\section{Conclusions}

In the current study, differences in design consideration for micro products were investigated and the consequent differences in design steps were identified. These differences were mainly observed in the "design requirements" which can be categorized in the following groups: 


- $\quad$ Material selection
- $\quad$ Manufacturing processes
- $\quad$ Shysical phenomena due to the size effect

Based on the mentioned differences, a micro specific design methodology was proposed and implemented in design of a micro heat exchanger. According to the design methodology, several primary design ideas were proposed based on the design principles for macro heat exchangers. By taking the differences in design considerations for micro products into account, second design ideas were created. Manufacturability criteria were defined and the most applicable micro manufacturing techniques for fabrication of the selected micro heat exchangers were identified and ranked based on the defined criteria, and the most appropriate manufacturing method was selected. The generated ideas were analyzed by numerical simulations and evaluated according to the design criteria (i.e. functional performance and manufacturability). The designs with higher functional performance and feasibility for fabrication were selected as the final designs. Finally, the effect of size in micro scale was investigated by comparing the thermal performance of the design for micro heat exchangers with their macro counterparts (i.e. 10 times scaled up) with regard to different materials and geometrical features (i.e. fin). The results of thermal analysis for the micro and macro heat exchangers fabricated from different materials with different thermal conductivities (e.g. copper, aluminum and polymer) showed that the thermal performance of a copper micro heat exchanger is only around $1-4 \%$ better than that made of aluminum, while this difference for their macro counterparts is around 6-11\%. Moreover, thermal performance of a micro heat exchanger of metal and low thermal conductive PMMA is only around 0-5\% less than that of pure metal, while this difference is up to $22 \%$ for its macro counterpart. Hence, the heat exchangers in micro scale are not noticeably influenced by the material variation while the material selection is considerably influential on thermal performance of the macro heat exchangers.

Evaluation of the thermal efficiency revealed that presence of fins in micro heat exchangers improves the thermal performance only around 3-7\%, while this improvement for their macro counterparts is around $29-58 \%$ which is considerably larger. This was expected due to significantly large Reynolds number and accordingly higher convective heat transfer coefficient in the macro scale as well as the small cross sectional area of the fins that causes high thermal resistance in the micro scale. Therefore, presence of the fins might not be necessary as they have insignificant role on thermal performance of the micro heat exchanger but increases the manufacturing cost, considerably.

Considering the challenges in manufacturing of the micro fins, several potential micro manufacturing techniques including micro end milling, micro EDM, micro $\mu \mathrm{MIM}$, micro casting and micro extrusion were ranked. Micro extrusion was suggested as the most suitable method for fabrication of the micro heat exchangers based on the manufacturability criteria by which the micro fins can be formed easily.

According to the above mentioned results and considerations for size effect, material selection, geometrical features and manufacturing processes, it was concluded that the micro aluminum heat exchanger without fin fabricated through the extrusion can meet the design requirements as the final selected design since the material and presence of the fins do not play important roles in this scale. The insignificant role of the fins on thermal performance of the micro heat exchangers can be considered as a useful point in design of micro heat exchangers to reduce the manufacturing cost considerably without major decrease in thermal performance of the micro heat exchangers.

The micro specific (size effect) information obtained through analysis of the modelling results by the designer during the evaluation of several design iterations was surprisingly different from what expected in macro scale such that the following guidelines in the RTC unit can be formulated:

- Presence of the micro fins inside the heat exchanger does not necessarily increase the thermal efficiency of the micro heat exchanger, significantly. 
- Low influence of constituent material of the heat exchanger's inactive parts (i.e. the lid) on the thermal performance shows the high potential of substituting the inactive parts made of high conductive materials (i.e. metals) with low conductive materials (i.e. polymers) and accordingly increase the manufacturing flexibility.

These can be considered as interesting micro-specific guidelines in the RTC unit which can be used by designers/engineers to significantly reduce the manufacturing cost, and increase the manufacturability of the micro heat exchanger, while preserving its functional performance.

The proposed methodology provides an interactive framework where the designer by evaluating the modeling results and the design criteria forms the RTC unit and employs it in the next design iteration of the micro product. Moreover, designers/engineers can use the knowledge-based RTC unit in design of the same category of micro products. In addition, the triggered RTC unit can be progressively enriched by designers/engineers through analysis of the modeling results in design process of other micro products and serve as a basic micro-oriented tool for design of micro products.

\section{References}

1. Qin Y (2006) Micro-forming and miniature manufacturing systems - development needs and perspectives. J Mater Process Technol 177:8-18. doi: 10.1016/j.jmatprotec.2006.03.212

2. Shah RK (2006) Advances in Science and Technology of Compact Heat Exchangers. Heat Transf Eng 27:322. doi: $10.1080 / 01457630600559462$

3. Popescu T., Marinescu M., Pop H., et al. (2012) Microchannel heat exchangers - Present and perspectives. UPB Sci Bull Ser D Mech Eng 74:55-70.

4. Marques C, Kelly KW (2004) Fabrication and Performance of a Pin Fin Micro Heat Exchanger. J Heat Transfer 126:434. doi: 10.1115/1.1731341

5. Julia S (2006) A System Design of Liquid Cooling Computer Based on the Micro Cooling Technology. Therm Thermomechanical Proc 10th Intersoc Conf Phenom Electron Syst 2006 ITHERM 2006 157-160. doi: 10.1109/ITHERM.2006.1645337

6. Harris C, Despa M, Kelly K (2000) Design and fabrication of a cross flow micro heat exchanger. J Microelectromechanical Syst 9:502-508. doi: 10.1109/84.896772

7. Fan W, Wong CK, Tan YM, et al. (2004) Design and Fabrication of Micro Thermoelectric Cooler on LTCC Substrate. $76-80$.

8. Darabi J (2003) Development of a chip-integrated micro cooling device. Microelectronics J 34:1067-1074. doi: 10.1016/j.mejo.2003.09.010

9. Scotti G, Franssila S (2014) A micro heat exchanger microfabricated from bulk aluminium. J Phys Conf Ser 557:012069. doi: 10.1088/1742-6596/557/1/012069

10. Kee RJ, Almand BB, Blasi JM, et al. (2011) The design, fabrication, and evaluation of a ceramic counterflow microchannel heat exchanger. Appl Therm Eng 31:2004-2012. doi:

10.1016/j.applthermaleng.2011.03.009 
11. García-Hernando N, Acosta-Iborra A, Ruiz-Rivas U, Izquierdo M (2009) Experimental investigation of fluid flow and heat transfer in a single-phase liquid flow micro-heat exchanger. Int J Heat Mass Transf 52:54335446. doi: 10.1016/j.ijheatmasstransfer.2009.06.034

12. Tjalve E (1976) Systematic design of industrial products. Copenhagen, Denmark

13. Yoshikawa H (1989) Design Philosophy: The State of the Art. CIRP Ann - Manuf Technol 38:579-586. doi: 10.1016/S0007-8506(07)61126-3

14. Cross N (2008) Engineering Design Methods: Strategies for Product Design. J. Wiley, Chichester, England

15. Alting L, Kimura F, Hansen HN, Bissacco G (2003) Micro Engineering. CIRP Ann - Manuf Technol 52:635-657. doi: 10.1016/S0007-8506(07)60208-X

16. Omidvarnia F, Hansen HN, Sarhadi A (2015) A systematic approach applied in design of a micro heat exchanger. Int J Adv Manuf Technol. doi: 10.1007/s00170-015-7401-y

17. Qin Y (2010) Micromanufacturing Engineering and Technology, Micro and Nano Technologies. William Andrew

18. Choi SUS (1995) ENHANCING THERMAL CONDUCTIVITY OF FLUIDS WITH NANOPARTICLES. ASME Int. Mech. Eng. Congr. Expo.

19. Heckele M, Guber AE, Truckenmüller R (2006) Replication and bonding techniques for integrated microfluidic systems. Microsyst. Technol. pp 1031-1035

20. Tsao CW, DeVoe DL (2009) Bonding of thermoplastic polymer microfluidics. Microfluid Nanofluidics 6:116. doi: 10.1007/s10404-008-0361-X

21. Ashman S, Kandlikar SG (2006) A review of manufacturing processes for microchannel heat exchanger fabrication. ASME 4th Int. Conf. Nanochannels, Microchannels, Minichannels. American Society of Mechanical Engineers, pp 855-860

22. Karniadakis G, Beskok A, Narayan A (2005) Microflows and Nanoflows. doi: 10.1007/0-387-28676-4

23. Baehr HD, Stephan K (2006) Heat and Mass Transfer. Springer; 2nd edition

24. Panton RL (2013) Incompressible Flow. WILEY, 4th Edition

25. Hattel JH, Pryds N, Thorborg J, et al. (2005) Fundamentals of numerical modelling of casting processes. Polyteknisk Forlag 